ing computer, as a three-dimensional model of the original photograph or image. The original ordinary two dimensions are preserved by the geometry of the scan and the third dimension is the measured grain density. The function of tho programme inserted into the computer is to 'look' at this three-dimensional model in a quantitative analytical way and measure values for parameters of interest. The word pattern reflects the fact that whatever the image is it will have a pattern which ean conveniently be described in terms of a series of parameters which can be measured. The weakness of the human eye and brain is their inability to make precise measurements on these parameters and remember them sufficiently accurately for purposes of comparison. Howevor, at least at present, the technique of pattern measurement still depends on the remarkable ability of the human eye and brain to recog. nize qualitatively the existence of parameters to describe the pattern of interest and thus make it possible to set up the appropriate programme for insertion in the computer.

Although devices for pattern measurement are not new developments, it is probably true to say that fairly recently, since the development of computer-typo transistorized circuits and their widespread use, a number of instruments have appeared or are being developed which raise quite exciting possibilities when one considers, for example, the wealth of beautiful photographs obtained with great care and labour and now stored away in laboratories throughout the world. In fact, the development of pattern measurement makes it even more worth while straining to obtain even better photographic records.

We shall be pleased to hear from laboratories, here or abroad, interested in the possibility of collaboration in applying our instruments for pattern measurement to an analysis of the data recorded on existing or projected photographs.

It is our intention, funds permitting, to continue with the development of successive models with even wider facilities, faster speed of scanning and specialized computer and inspection facilities built into the original instruments. In this field, the continued development of genuinely useful instruments depends on the feed-back of experience gained by practical applications.
As a result of such feed-back we have come to the conclusion that, in general, there is no need to consider really large generalized computers even when pattern measurements are being made on complex images which require very large numbers of points to describe them adequately. The use of such computers is really only necessary if one insists on inserting all the information obtained, by scanning a complete image, before commencing the process of analysis. A study of our programme using the mark I instrument suggests strongly that it is worth considering pattern measurement instruments in which one, two or perhaps three lines only are scanned at a time and stored temporarily. This would be followed by immediate analysis using small specialized computer units to extract provisional values for the parameters of interest. These parameters are relatively few in number compared with the total number of points on one or two lines, and the provisional (or line) values of the parameters can be stored for subsequent analysis by a small final computer unit when all the image has been scanned and all the provisional values obtained. This separation of the computer analysis into two parts, provisional and final, is the major difference in our own work and similar efforts in the United States. It does not seem to introduce any great limitations for most images, it avoids the expense of time on large computers which can include the rental of land lines. Perhaps best of all, it opens up the real possibility of relatively inexpensive pattern measurement instruments for individual laboratories where the entire operations and the results are immediately in the hands of individual workers, thus allowing the all-important changes and adjustments which occur in any practical developing project.

This and other points are included in the projected instruments, now being designed here.

We acknowledge the provision of funds by the Depart. ment of Scientific and Industrial Research which enabled us to pursue this work, and the award of a D.S.I.R. research studentship to one of us (G. W. McM.). We also thank Mr. Donald Chadney of General Electric Co., Ltd., for his skilful choice of circuitry and components in the design and the successful construction of our present mark I instrument.

\title{
OBITUARIES
}

\section{TWO PIONEERS OF PEST CONTROL}

$\mathrm{B}^{\mathrm{x}}$ strange coincidence the two scientists who had the greatest influence on the development of the initially independent firm of Pest Control, Ltd., died within a few months of one another. Dr. W. E. Ripper crashed in the snow-covered mountains of Greece on March 21, 1965 , while on a solo flight, though this fact was not known with certainty until his remains were discovered in June. Dr. E. Parry Jones died in hospital after a long illness, follow ing a longer period of failing health, on June 30 .

Both were trained as entomologists. Both gave the best years of their lives to control of pests in agriculture and particularly through their service to the same Company. Their abilities, service and successes were largely complementary. Both brought to bear talents which are essential for the development of a technically based industry. Ripper was essentially an initiator, a creator; sometimes ruthless, sometimes careless under his powerful inner drive to get things going. Parry Jones appeared far more conservative, but this was largely the response of a strongly self-disciplined man to the circumstances he had to face. Ripper's policy had brought the Company into a difficult financial position, and Parry Jones was insistent that, in the next phase of devolopment, novelty and originality had to be kept within the framework of the commercially practicable.
The nature of the untimely death which overtook these men is in a strange sympathy with this difference between them. Ripper's friends had always advised him to forgo his passion for solo flying owing to deterioration of his eyesight, but he was an irrepressible enthusiast for physical as woll as mental action, a keen skier and waterskier. He would perhaps have preferred to leave this world suddenly at the height of his powers. Parry Jones, also a keen sportsman in his younger days, had known himself to be in declining health for a long time owing to serious failure of lung capacity. He would not openly admit it, certainly never make a fuss about it, and strongly resented any tendeney on the part of his colleagues to do so, but it was elear that he carefully conserved his physical energy and knew that he had to do so. Perhaps the discipline he had to apply to himself helpod him to apply a similar disciplino to the Company which he nursed round, after its acquisition by Fisons, Ltd., to become Fisons Pest Control, Ltd., from a position of considerable financial loss to one of sound financial profit.

These two men, in their different ways, were leaders in the field of applied science. Without tho one the Company of Pest Control would never have started. Without the other it would not have survived the problems of adolescence. 'The death of both will be a great loss to many. 